\title{
XXII. Experiments on anthracite, plumbago, \&c.
}

\section{Lardner Vanuxem}

To cite this article: Lardner Vanuxem (1825) XXII. Experiments on anthracite, plumbago, \&c. , Philosophical Magazine Series 1, 66:329, 161-167, DOI: 10.1080/14786442508673942

To link to this article: http://dx.doi.org/10.1080/14786442508673942

曲 Published online: 10 Aug 2009.

Submit your article to this journal $\pi$

III Article views: 2

Q View related articles $₫$ 


\section{PHILOSOPHICAL MAGAZINE AND JOURNAL.}

$30^{\text {th }}$ S E P TE M B E 1825.

XXII. Experiments on Anthracite, Plumbago, \&c. By Lardner Vanuxem.**

THESEE experiments were undertaken with a view to determine whether the globules obtained by Professor Silliman, from the above substances, were owing to a fusion of their carbon, or merely to the impurities or foreign matter contained within them $t$. They were long delayed by my waiting for some sheet zinc necessary to repair a deflagrator intended to be used for the purpose of obtaining the globules; but this not arriving, I resolved to avail myself of the suggestion of Professor Silliman; namely, that of using the compound blowpipe, which answered perfectly well. In the experiments with the blowpipe, the substances were placed upon platina foil, spread upon a lump of magnesia; the size of the pieces subjected to its action was about half an inch in diameter and a quarter of an inch in thickness. The light in the greater number of instances was so intense, that I found it necessary to use double green glasses.

The mode pursued in the analysis of anthracite and plumbago was as follows. The presence of water was ascertained by heating a few small pieces of the substance in a glass tube closed at one end; and the quantity of water, by heating a given portion in a covered platina crucible. Another portion was pulverized in an agate mortar; then a given weight of it was put into a platina crucible, and kept without its cover at a red heat in a small French furnace until the whole of the carbon was consumed; the residue was then boiled in water for an alkali; after which operation it was heated with caustic potash in a silver crucible: when the fusion of the mass was completed, water was added, and the whole then dissolved

* From the Journal of the Academy of Natural Sciences of Philadelphia, for June 1825.

$\uparrow$ See Phil. Mag. vol. lxiv. p. 467; vol. lxv. p. 283.

Vol. 66. No.329. Sept. 1825.

with 
with nitro-muriatic acid. By evaporating the liquor to dryness, and adding acidulated water and filtering, the silex was obtained. To the liquor from this operation ammonia in excess was added; and by this agent, the iron, manganese, and alumine contained in the liquor, were precipitated; the latter was separated from the two former by caustic potash. No attempt was made to ascertain the relative proportions of iron and manganese, this knowledge not being considered important. The presence of manganese was evidenced by the green colour of the alkaline fusion; and a rose-colour, when acid was added to the liquor. No allowance was made for the difference in the degree of oxidation of the iron and manganese in the substances used, and the products obtained, as the amount was less than one per cent, where most abundant.

The first experiments made with the globules were with potash and with carbonate of soda, on silver and on platina foil: with these agents I could not produce much effect; hut by using a small quantity of carbonate of lime, carbonate of soda and borax, on platina foil, their fusion, whether they were coloured or colourless, opaque or transparent, was effected in a few minutes.

Euxperiment 1.-A piece of the purest anthracite of Lehigh, subjected to the blowpipe, presented numerous small white globules; few were tinged with violet, and two or three were blackish; the globules did not readily unite with one another : however, by long continued heat, some of the globules were obtained of the size of the head of a small pin; the greater number of them were but feebly translucent, and could be broken by a moderate force; others, though few in number, were transparent, hard, and not so brittle. The white globules were not magnetic, except when dark spots were present; the blackish ones were magnetic, and like the whole of them could be fractured by pressure. The surface of the mass whitened, as observed in the ordinary combustion of this coal, and presented veins or layers of the matter of the white globules, showing that the impurities of the coal were not regularly intermixed with its carbon, or, upon the supposition of its being fused carbon, that its production was extremely irregular.

With the flux before mentioned the different kinds of globules were melted without difficulty. By heating a centigramme and a half of the globules in powder, for a long time, with caustic potash, about 3-4ths of a centigramme of silex was obtained. It manifested itself by its gelatinous appearance before the water was driven off. 
The result of the analysis of this anthracite was

Carbon ................... 90.1

Water*................... 6.6

neration, of a Alumine .... $1 \cdot 1$

$\left.\begin{array}{l}\text { dirty white co- } \\ \text { lour ..... }\end{array}\right\} 3.3$ consisting of $\left\{\begin{array}{c}\text { Oxides of iron } \\ \text { and manganese }\end{array}\right\} 0.2$

Experiment 2.-The anthracite of Rhode Island, by the action of the blowpipe, presented a brownish appearance after cooling (owing to manganese). The surface exhibited numerous globules, larger than those of the Lehigh : some of them were transparent, colourless, and very brilliant by reflected light; others, and the most abundant, were black and opaque, and were strongly attracted by the magnet; a few were coloured white and black in spots, the white spots resembling enamel. The surface of the mass presented minute veins similar to those of the Lehigh.

Some of the black globules were heated for a long time on platina foil, with carbonate of soda; the mass was yellowish, but became black when immersed in water. By heating and dipping into water several times, the globules whitened: I could not effect their fusion in this way, but with the compound flux they readily fused. With this flux the different kinds were tried, and with the same effect.

The analysis of this anthracite from Rhode Island gave

Carbon .. . . . . . . . . . . . . . . 90.03

Water . . . . . . . . . . . . . . . . 4.90

Residue by inci- (Silex .... 2.14

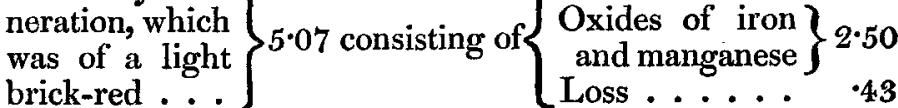

brick-red ... [Loss .....

$100 \cdot 00$

Another specimen from the same locality, whose colour was a little different, being of a deeper black, and which was not tried with the blowpipe, gave

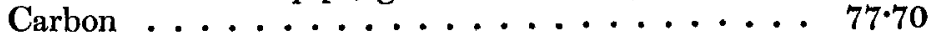

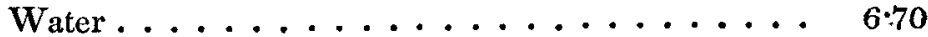

Residue by inci-) Silex ..... 8.50

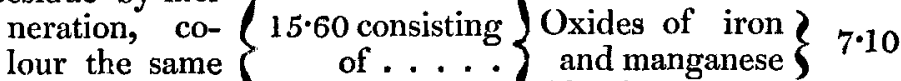
$\left.\begin{array}{l}\text { lour the same } \\ \text { as the former }\end{array}\right\}$ of ....

$\overline{100 \cdot 00}$

* It is rather singular that so great a quantity of water as is contained in anthracite should heretofore have escaped notice. It is $\mathrm{my}$ intention to examinc all the different kinds of coal, to ascertain if this fact be general. 
Experiment 3.-A specimen of plumbago from Borrowdale, of great purity, as judged by its external characters and mechanical properties, was subjected to the blowpipe: the globules began to form immediately and in great number, attended occasionally by scintillations, owing to the combustion of iron; the globules were small; the greater part of them were black, opaque, and of great lustre; others were dull, of a brownish colour, and feebly translucent : almost all of them were attracted by the magnet. The surface of the heated part of the plumbago was brownish.

The globules, though acted upon with great difficulty by soda, and by potash, readily yielded to the compound flux, and formed a limpid yellowish glass. A large globule, by repeatedly heating it with carbonate of soda and plunging it into water, became rough; and finally opened in the centre; it then dissolved in nitro-muriatic acid. By evaporating the liquor to dryness, the yellow colour of the iron-was very manifest; acidulated water took it up, leaving a white substance like silex floating in the liquor.

The analysis of this plumbago gave

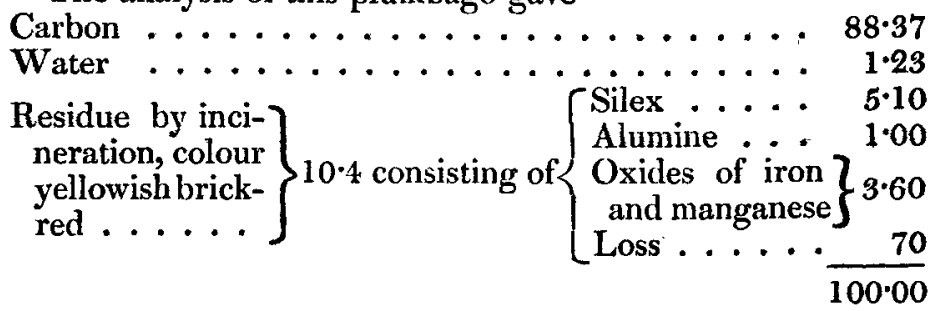

Experiment 4.-An impure specimen of plumbago from the same locality gave numerous and large globules, some of the size of small shot; they readily formed: the majority of them were translucent, shining, and of a light greenish-yellow; others were dark-coloured; and some of them were dull externally. The dark globules, as well as the surface of the mass of plumbago exposed to the flame, were attracted by the magnet; some of the light-coloured ones were affected by the magnet, but only at the point where they had been attached to their support, owing to particles of the support adhering to them. During the combustion of the plumbago, there were occasionally scintillations; the heated surface of the mass was brownish.

A large globule of the lightest colour and magnetic only at one point, melted with ease when the compound fiux was used; it formed a transparent mass when hot, and opaque and milky when cold. The black ones with the same flux were also fused; they were brownish when hot, and greenish when cold.

They 
They were acted upon with great difficulty by caustic potash, and by carbonate of soda.

The analysis of this plumbago gave

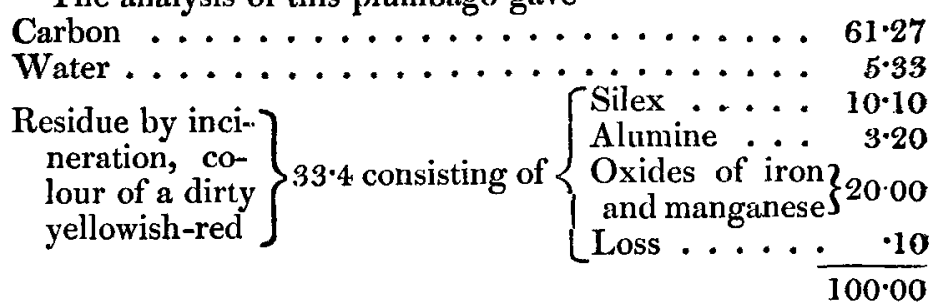

Experiment 5.-A specimen of plumbago remarkably pure, from near Bustletown, Pennsylvania, was tried with the blowpipe. The globules were formed with difficulty, probably owing to its foliated texture, the fused parts spreading over the surface. The colour in places was white and translucent, in others so dark as to be almost black.

With the flux before mentioned the fused matter was reduced to a transparent glass.

The analysis of this plumbago gave

Carbon .................. 94. . . 40

Water..................... 0.60

$\left.\begin{array}{c}\text { Residue by inci- } \\ \text { neration, colour } \\ \text { light brick-red }\end{array}\right\} 5.0$ consisting of $\left\{\begin{array}{l}\text { Silex } \ldots \ldots \\ \text { Oxides of iron } \\ \text { and manganese } \\ \text { Loss } \ldots \ldots \frac{1 \cdot 00}{100 \cdot 00}\end{array}\right.$

Similar experiments were made with plumbago from several other localities; the results of which were nowise different, and therefore need no further mention.

Experiment 6.-A piece of charred mahogany, during its combustion by the compound blowpipe, presented numerous small imperfect globules, owing to the force of the flame, which dissipated their support before they had time to form or to accumulate to any considerable size: many of them adhered together, ramifying like flos ferri, which they resembled. They were collected by placing a dish under their support. By the compound flux they readily fused into a transparent glass.

Experiment 7.-A quantity of lampblack was pressed into a mould with great force, and made to assume the form of a cylinder of about 3-4ths of an inch in diameter and half an inch in thickness; it weighed seven grammes. This cylinder of lampblack was subjected to the blowpipe. It wasted away gradually, without forming any globules or fused matter visi- 
ble to the naked eye or to the microscope. The heat was equally as intense in this experiment as in all the other instances, and no condition was wanting to produce the same effects, except the difference of composition. After burning the lampblack for as long a time as was thought necessary to make the experiment a fair one, it was again weighed, and found to have lost four grammes $\frac{42}{100}$, for it weighed but two grammes $\frac{58}{100}$.

Five grammes of the same lampblack, heated in an open platina crucible, left after its incineration one centigramme of white ashes, equal to $\frac{1}{5} \overline{0}$ of the mass.

From the analyses of the substances used by Professor Silliman, from which the globules were obtained, it appears that they all contain foreign matter, as silex, iron, manganese, and some of them also alumine; that when lampblack was used which contained but ${ }_{500}$ of fixed impurities, no distinct globule or melted matter was formed, although the heat was sufficiently great, and the combustion slow enough to admit of the forming of globules, if their production was owing to the fusion of carbon, and not to extraneous matter. From my own experiments I always found that the more impure the substance was, the more numerous and the larger were the globules produced.

All the globules from the different kinds of substances used were readily fused by the compound flux, and underwent little change when it was not used; although the heat was, in this case, of longer continuance. Matter similar to the impurities discovered in the substances used was detected in them.

From these facts it would appear, that the globules produced from the combustible substances operated upon did not arise from the fusion of their carbon, since they can otherwise be accounted for; particularly as no experiment has been made which unequivocally leads to that conclusion. The experiment upon which Professor Silliman relies, as a proof of the globules being fused carbon, is one which is not satisfactory to me; if it had been, it would have given me great pleasure, for no one, I trust, feels more interested in the scientific prosperity of his country than I do; and if Professor Silliman were right, it would indeed be a triumph for America.

The experiment just alluded to (see Journal of Science, vol. vi. p. 347, ) is the heating some of the coloured globules in oxygen gas by the solar rays, with a lens. The following is an extract from the papers.

"' To detach any portion of unmelted plumbago which might adhere to them, I carefully rubbed them between my thumb 
and finger, in the palm of my hand. Although they were in the focus for nearly half an hour, they did not melt, diappear, or alter their form; it appeared, however, on examining the gas, that they had given up a part of their substance to the oxygen, for carbonic acid was formed which gave a decided precipitate with lime-water."

That this experiment is equivocal appears certain, as particles of the support might have been attached to the globules; for, from my own observations, I found that in a great number of instances, some of the white globules at the point of junction with their support had small dark particles attached to them; and when the surface from which they were detached was magnetic, they were attracted by the magnet when it was presented to those parts: I could not disengage those particles by rubbing the globules with my fingers against one another. It is very evident that, as the globules underwent no change (unless a reduction of volume, which is not mentioned), as the description clearly shows, the carbonic acid obtained might have been produced by the combustion of portions of the support adhering to them externally, and penetrating them to a certain extent.

In the experiment detailed in vol. v. p. 363, of the same Journal, the carbonic acid found probably had a similar origin, and the disappearance of the globules may have been owing to their incorporating themselves with the piece of brick upon which they were placed, as the brick was vitrified at the point where they were placed.

Professor Silliman seems disposed to lay great stress on the loss in my examination of the globule sent by Dr. Macneven. I thought I had well accounted for it, as the particle was small, action violent, and I merely wished to show chemically the presence of iron. I could not for one moment entertain the idea that carbon existed in it, in any notable proportion; for I know of no combination of iron and carbon, at common temperature, which could give a product possessed of the malleability and toughness which the globule possessed.

I was sorry to observe that Professor Silliman in his reply to my paper seems offended that I did not notice his communications upon the subject of these globules, particularly as the discovery was his, and was justly entitled to such consideration. My silence certainly appeared uncourtly; but it was not owing to ignorance of his labours, or a want of regard to him personally, or as a chemist; Professor Silliman's merit is too well known to be affected by me.

XXIII. On 